\title{
Family Studies of Alzheimer's Dementia: Results and Prospects
}

\author{
Leonard L. Heston and Marcia L. Morris
}

\begin{abstract}
Studies of families located through a proband with dementia of the Alzheimer type have demonstrated transmission of the disorder within families, probably through shared genes. Increasing closeness of genetic relationship and increasing severity of illness are both associated with increasing risk to relatives. Families ąt high risk are especially valuable for studies of the biology of dementing illness including, in particular, their molecular genetics. Associations at several levels between Down's syndrome and Alzheimer's dementia provide important clues for molecular hypotheses.
\end{abstract}

RÉSUMÉ: Etudes familiales dans la maladie d'Alzheimer: résultats et perspectives. Des études de familles répérées au moyen d'un cas index, atteint de démence de type Alzheimer, ont démontré la transmission de cette affection dans les familles, probablement par des gènes communs. Une relation génétique plus étroite et une sévérité plus grande de la maladie sont associées à un risque plus grand pour les individus qui leur sont apparentés. Les familles à risque élevé sont particulièrement précieuses pour étudier la biologie du processus démentiel et surtout pour les études de génétique moléculaire. Des associations sur plusieurs plans entre le syndrome de Down et la démence de la maladie d'Alzheimer fournissent des indices importants pour l'élaboration d'hypothèses moléculaires.

Can. J. Neurol. Sci. 1986; 13:432-434

Relatives of probands with dementia of the Alzheimer type (DAT) have rates and distributions of dementing illness which support an etiological contribution from genes. At specified ages, rates are significantly higher for such relatives than for members of the general population, and are higher for first degree relatives than for second degree relatives.

The highly age specific nature of these incidence rates warrants underscoring. Figure 1 displays incidence rates graphically with ages at onset on the abscissa. About $0.7 \%$ of those at risk become affected each year. Because there is a constant increment of new cases each year, the cumulative incidence approximates a straight line as can be seen in Figure 1. This applies to any population so far studied including general populations. The difference among populations is the age at which the risk begins and becomes appreciable - where on the abscissa the graphed line originates. For the general population this is about age 65. For first degree relatives of DAT cases it is about age 55; and for rare families at very high risk, it is age 40-45. Thus the practical effect of having a first degree relative with DAT is to shift the expected age at onset toward youth.

\section{Severity}

A major feature of the clinical genetics of DAT is the relationship between risk to probands' relatives, specifically the age at which the risk begins, and relative severity of illness. In all studies so far which present the relevant data, probands have been several years younger at onset of illness than their affected relatives (secondary cases). In our studies at Minnesota, only $10 \%$ of secondary cases experienced onset of illness at a younger age than the proband through whom the family was located. ' This is entirely compatible with general experience in medical genetics. Probands tend to be selected for relatively flagrant, dramatic disease, which implies more severe disease. This finding suggests that relative severity of illness is an important parameter. It also has obvious implications for genetic counseling and a more subtle one for genetic analyses: many methods of biometric analysis assume equal risk at given ages for probands and their relatives. Obviously, this assumption is untenable in DAT. The difference between ages of onset for probands and secondary cases can be seen in Table 1. 
Greater relative severity implies greater risk to relatives at given ages. In general, this implication seems born out by empirical study. In the Minnesota studies, the younger the onset of proband's illness, the greater the risk to relatives.' However, the numbers of families studied is too small to establish this relationship conclusively. A major problem in this context is a ceiling effect imposed by the human life span. This is the more pertinent because probands are much younger than secondary cases. For example, secondary cases in the families of probands age 75-79 at onset of illness, would have expected onsets in their late 80's. A small proportion of the population lives long enough to be at risk at those ages, and those who do survive are likely to have chronic illnesses which confound clinical evaluations of mental function.

\section{Family Studies}

Figure 1 shows incidence rates among siblings of DAT probands reported in 5 major modern studies. Each study found about the same rate of increased risk - the lines depicting cumulative risks are nearly parallel - but the ages at which their risks apply differ - the origins on the abscissa differ. A plausable explanation for this is provided by the relative severity of illness among probands. Most of Larsson's probands were age 65 or older at onset of illness and were found in a general population. Åkesson's probands were also 65 or older at onset but were found in nursing homes. To be included in the

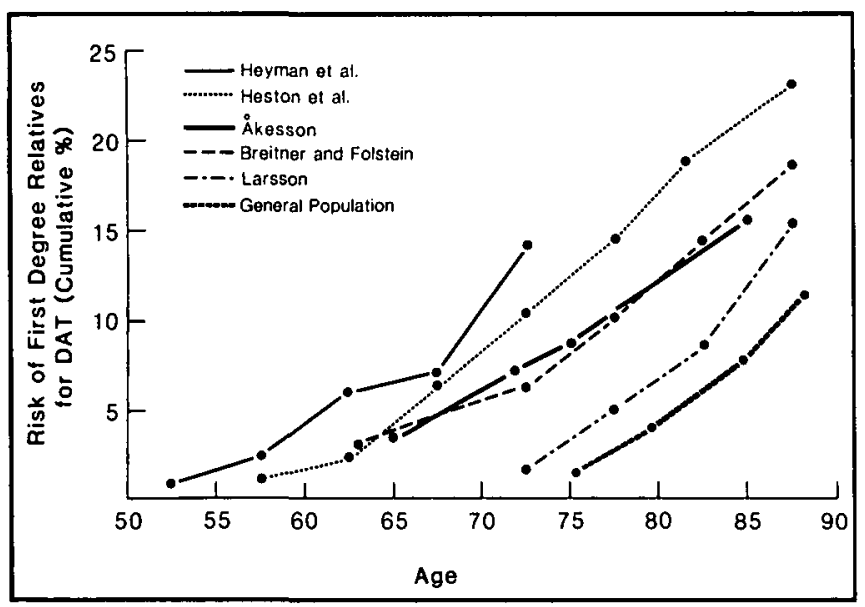

Figure I - Cumulative incidence of DAT among siblings of probands. Note the effectively straight and parallel lines produced suggesting a constant risk which was found independently by each study. Possible reasons for the differences in origin on the abscissa are discussed in the text. Data are from Heston et al, ${ }^{1}$ Heyman et al, ${ }^{2}$ Sjögren et al, ${ }^{3}$ Larsson et al, ${ }^{4}$ and Breitner and Folstein.

study, they had to be constantly disoriented. Heston's probands were of all ages. They came from a series of autopsies done in Minnesota state hospitals between 1952 and 1972 and were unselected except for permission for autopsy. This is the only series with pathologically confirmed diagnoses. Breitner's probands were potentially of any age but there was likely some oversampling of older cases. Heyman's probands were all less than age 65 at onset of illness. The results depicted in Figure 1 are entirely in line with expectations based on relative severity of illness among probands. Until new hypotheses are developed, family studies of the type depicted in Figure 1 would seem increasingly repetitious.
Table 1: Differences in age at onset of DAT for probands and their affected relatives. In years.

\begin{tabular}{lccc}
\hline Study & $\begin{array}{c}\text { Proband's Relative's } \\
\text { onset }\end{array}$ & onset & Difference \\
\hline $\begin{array}{l}\text { Heston et al }{ }^{1} \text { all cases } \\
\text { Heston et al Proband's onset }\end{array}$ & 66.0 & 71.1 & 5.1 \\
$\quad$ age 65 & 57.8 & 69.5 & 11.7 \\
Heyman et al & & & \\
Larsson et al $^{4}$ & 58.6 & 65.7 & 7.1 \\
\hline
\end{tabular}

Heston et al found 9 of 87 secondary cases to be younger at onset of DAT than the proband through whom the family was located. For Heyman et al the numbers were 3 of 22 .

\section{Downs and DAT}

That persons with Downs syndrome develop neuropathological changes identical under the light or electron microscope with those found in DAT is well established. By age 40 , all Downs brains which have been examined exhibit the plaques and tangles which delimit DAT. ${ }^{7}$ The risk of persons with Downs for DAT pathology approaches $100 \%$, since so far, no exception has been reported. In addition, the risk for pathologic change begins at much younger ages for persons with Downs than for normals. Finally, Downs brains exhibit the same patterns of enzyme changes, particularly in cholinergic markers, as do DAT brains.

Several other associations between Downs and DAT are also potentially important. Both Heston and Heyman found excess Downs cases among relatives of probands with DAT. ${ }^{1,2}$ Weinreb found that dermatoglyphic patterns on fingers, palms and soles of DAT cases deviate in the direction of Downs cases. None of several neurological, retarded, and normal controls exhibited like deviations ${ }^{8}$ Later, Weinreb reported that in early onset DAT cases, sweat glands were relatively rare compared to normals, had irregular structure, and were often plugged. ${ }^{9}$ These changes are also analogous to those reported in Downs.

Whether or not Downs develop dementing illness corresponding to the neuropathology is still controversial. No cohort of Downs cases has been studied longitudinally by psychometric testing through the risk period. However, cross sectional studies have discovered progressive loss of cognition; older Downs score lower than younger ones. ${ }^{11,12}$ While the proportion of Downs destined to develop brain failure before death is unknown at this time, the available evidence suggests that the proportion may be a large one.

\section{CuRRent Research}

We are currently engaged in a 15 year follow-up of the families we have been studying. One aim is to further refine the incidence estimates, especially those applicable to children of probands with DAT. More important, we are using tissue samples from families at highest risk to begin exploration of molecular hypotheses. Our hypotheses are based on the association between Downs and DAT. We assume that there is a near 100\% incidence of DAT in older Downs cases. Since Downs would presumably inherit a gene(s) associated with DAT in nontrisomic normals at rates comparable to those in a general population, phenotypic DAT in any large proportion of Downs cases could hardly be attributed to segregating genes. We think that phenotypic DAT in Downs, like other features of the 
Downs phenotype, is likely associated with excess product of genes of chromosome 21 . Such gene products would be structurally normal but would be present in excess because of the excess DNA present in Downs. Moreover, only a small segment of chromosome 21 is required: the Downs phenotype is associated in $3-4 \%$ of cases with a trisomy of only the $21 \mathrm{q} 22$ segment of chromosome 21 . Since products coded for by $21 \mathrm{q} 22$ are associated with DAT in Downs, we assume as a working hypothesis that the same products may be associated with DAT in non-Downs.

Three genetic loci have been mapped to the 21 q22 segment. These are: the interferon receptor complex (AVG); superoxide dismutase-1 (SOD-1); phosphoribosylglycinamide synthetase (GARS). For all three loci, Downs cases produce more gene product than normals. To continue the analogy between Downs and DAT we ask whether these loci produce more product in DAT tissues than in control tissues. The answer is mixed. Sensitivity to the anti-proliferative effect of interferon is increased in lymphocytes from DAT cases which suggests that more interferon receptor is present. ${ }^{12}$ However, other investigations pertaining to interferon receptors in DAT have been inconclusive. ${ }^{13}$ SOD-1 is apparently increased in fibroblasts from DAT cases. ${ }^{14}$ It is also increased in brain. ${ }^{15.16}$ GARS levels have not been estimated in DAT.

How could a few genes on 21 q22 produce excess product in mid-life leading to phenotypic DAT? One possibility is that in DAT a short piece of chromosome 21 is actually present in triplicate - a "partial trisomy". We regard this as unlikely because widespread and intensive searches of karyotypes have not disclosed such an abnormality and because DNA concentration in DAT brain appears not to be increased. ${ }^{17} \mathrm{~A}$ second possibility is that transcription of a subset of genes in the 21 q22 segment is increased in DAT. This is the possibility we have elected to explore.

\section{HYPOTHESIS}

We suggest that a DNA enhancer sequence inserts into a critical area of chromosome 21 . Such sequences act in cis to increase transcription from small subsets of genes independent of $3^{\prime}$ to $5^{\prime}$ orientation. Since their discovery in DNA tumor viruses, enhancers have become increasingly well known. They have been found within the genomes of several viruses and in association with the human immunoglobin gene complex. ${ }^{18,19}$ With respect to DAT, an enhancer could explain changed activity of several gene products, could be influenced by age or tissue specific factors, and could account for the observed transmission within families.

We have elected to map restriction fragment length polymorphisms in high risk families as a first step in exploring this hypothesis. Happily, mapping itself could discover significant linkages. Also, the 21 q22 area is now only crudely mapped. Determination of gene order and the actual sequence of nucleotides in at least part of the DNA will be needed before detection of an enhancer sequence would be possible. Accordingly, in collaboration with Harry Orr, a molecular geneticist, we have been collecting blood from high risk families, establishing lymphoblast cell lines, and will shortly use a SOD-I cDNA probe to begin molecular exploration of the relevant area. Obviously, this is just a beginning. But when we reflect that a couple of decades ago effectively nothing at all was known about DAT, we think that we have come a long way indeed.

\section{REFERENCES}

1. Heston LL, Mastri AR, Anderson VE, White J. Dementia of the Alzheimer type: Clinical genetics, natural history, and associated conditions. Arch Gen Psychiatry 1981; 38: 1085-1090.

2. Heyman A, Wilkinson WE, Hurwitz BH, Schmechel D, Sigmon AH, Weinberg T, Helms MJ, Swift M. Alzheimer's disease: Genetic aspects and associated clinical disorders. Annals of Neurology 1983; 14: 507-515.

3. Sjögren T, Sjögren H, Lundgren AGH. Morbus Alzheimer and Morbus Pick: A genetic clinical and patho-anatomical study. Acta Psychiatr Neurol Scand 1963; suppl. 92.

4. Larsson T, Sjögren T, Jacobson G. Senile dementia. Acta Psychiat Scand 1963; (Suppl. 167), 39: 1-259.

5. Breitner JCS, Folstein MS. Familial Alzheimer Dementia: a prevalent disorder with specific clinical features. Psychological Med 1984; 14: 63-80.

6. Akesson HO. A population study of senile and arteriosclerotic psychoses. Human Heredity 1969; 19: 546-566.

7. Malamud N. Aging and the Brain. Gaits CM, ed. pp 63-87, 1972; Plenum Press, New York.

8. Weinreb HJ. Fingerprint patterns in Alzheimer's disease. Archives of Neurology 1985; 42: 50-54.

9. Weinreb HJ. Microdermatoglyphic Patterns in Alzheimer's disease. American Academy of Neurology meeting, April 1986 (abstract).

10. Haxby JV. Clinical and neuropsychological studies of dementia in Down's syndrome, pp. 572-575. In: Cutler NR, moderator, Alzheimer's disease and Down's syndrome: new insights. Ann Intern Med 1985; 103: 566-578.

11. Thase ME, Liss L, Smeltzer D, Maloon J. Clinical evaluation of dementia in Down's syndrome: A preliminary report. Journal of Mental Deficiency Research 1982; 26: 239-244.

12. Weinreb HJ. Enhanced lymphocyte interferon sensitivity in Alzheimer's disease. American Academy of Neurology meeting, April 1986 (abstract).

13. Mowshowitz SL, Dawson GJ, Elizan TS. Antiviral response of fibroblasts from familial Alzheimer's disease and Down's syndrome to human interferon-alpha. J Neural Transmission 1983; 57: $121-126$.

14. Theinhaus OJ, Cliffe C, Zemlan FP et al. Superoxide dismutase in fibroblasts: possible chromosome 21 abnormality in Alzheimer's disease. Am Psychiatric Assn meeting, May 1985 (abstract).

15. Scott M, Panter S. Personal communication.

16. Marklund SL. Superoxide dismutase- 1 in Alzheimer's disease brain tissue. JA Neurol Science 1985; 67: 319-323.

17. Cook-Deegan RM. Implications of normal lymphocyte DNA content in familial Alzheimer's disease. American Journal of Medical Genetics 1983; 15: 511-513.

18. Hamer DH, Khoury G. Enhancers and Eucaryotic Gene Expression. Gluzman Y, Shenk T., eds. Current Communications in Molecular Biology. pp. 1-15, 1983, Cold Spring Harbor, New York.

19. Mercola M, Goverman J, Mirell C, Calame K. Immunoglobulin heavy-chain enhancer requires one or more tissue-specific factors. Science $1985 ; 227: 266-270$. 